\title{
Free Software as an Option for Ship Design
}

\author{
Bastiaan N. Veelo, NTNU ${ }^{1}$
}

\section{Software for a Special Purpose}

Maritime industries put special demands on computer applications. Advanced general purpose engineering design software (covered by the term "Product Life-cycle Management", PLM) is successful in many other branches of engineering. But, despite their level of sophistication, they often fall short of our demands. Of course, computer applications exist that address some of our special needs, but because the market is relatively small, these products usually have one or more of the following disadvantages:

1. Limited functionality; especially functionality that is common in PLM applications may be lacking.

2. Often the user interface is not as productive as the interface of commercial PLM in general engineering.

3. High licence fees for the user.

4. Low profitability for the producer.

Because of these disadvantages and the shortcomings of mainstream CAD systems, able naval architects develop custom software, probably to address a few issues initially. An important advantage of such an effort, besides now being able to address particular issues, is access to the source code.

\subsection{Access to Source Code}

Most software that you buy does not actually become your property, but you buy a license to use the software in its binary form. Any attempt to "reverse engineer" its inner workings is often explicitly prohibited. The knowledge that is represented by the source code of the program is a secret fiercely protected by its licensor, and as a licensee you cannot extend or evolve the software.

Access to source code gives you various privileged abilities, provided you have the required technical skills:

- To fix bugs

If you discover a bug in commercial software (in binary format), you can only report the bug to the vendor, wait for the next version to be released and pay an upgrade license. This new version may or may not fix the bug, and almost certainly introduces new ones. With access to the source code you can track down the problem yourself and probably fix it yourself.

- To inspect it

You can assess the correctness of its algorithms, and with it, the validity of the results that it produces.

- To customise it

The software may have been written to assist in the solution of one specific problem. Later, you may encounter a similar problem. You can adapt then the software to also assist in the solution of this new problem.

- To extend it

You have the possibility to extend it so that it can perform more diverse tasks for you.

\footnotetext{
${ }^{1}$ Frode Rinnans vei 60, N-7050 Trondheim, Norway, Bastiaan.N.Veelo@ntnu.no
} 


\section{- To evolve it}

There is always room for improvement, e.g. in the user interface, in the efficiency of its algorithms, in the accuracy of its output, to support new hardware or to make use of performance features of new processors. Access to the source code gives you the opportunity to make general improvements, or even experiment with alternative approaches to the problem.

These privileges are so valuable that they sometimes are the main motivator for an in-house programming effort, Mutu et al. (2003).

\subsection{Parallel Efforts}

Raymond (1999) gives "empirical evidence that approximately $95 \%$ of [source] code is still written in-house", and nearly all ship design software available today started out as an in-house or even personal project. However, few of these initiatives grow out to produce a tool that others are willing to pay for. As software development usually does not belong to the core activities of a design office, there are not enough resources to raise the software to professional software vendor quality (stability, efficiency, ease of use, user manuals etc.), nor for support and maintenance that commercial distribution of the software would require. Thus, there is a considerable programming effort that is not exploited to its full potential.

\subsection{The Conventional View Reviewed}

In-house software developers frequently assume that the secrecy of their software increases their competitive position. However, chances are that competitors also use in-house developed software, limiting the real advantage of mutual secret efforts. Alternatives are:

- Give the software away in binary form

As you are not making any money on the software, and its value for your competitive position is debatable, one option could be to give it away. You can try to create a small revenue stream by making it "share-ware", where people can pay a fee to make an advertisement notice go away. But, as the state of the software is below production quality, it is not likely to be of much use to anybody outside your department, not without the support that you are not interested to provide, and few will think it is worth paying the share-ware fee. The benefits for you are practically zero, unless you manage to turn it into a marketing stunt and attract attention to your core business, and for others the benefits are close to zero. You should disclaim any warranty for the correctness of the software and the validity of its output, which you cannot afford without the software creating revenue, so serious application of the software is not attractive for third parties.

- Publish the source code

This option includes the former one, because anyone will be able to compile the software into binary form. Source code is automatically protected by international copyright law, as per the Berne Convention of 1886 , meaning that no registration is required, nor is the inclusion of a copyright notice. No-one is allowed to make copies of source code or make changes without permission of its originator.

With the availability of the source code, third parties can now inspect it and assess the correctness of the software, and theoretically decide to use it to solve real-world problems. However, source code analysis requires a considerable effort, and copyright law prohibits third parties to exploit the typical advantages mentioned in section 1.1, meaning that they will have to accept a low level of quality and lack of vendor support. The protected advantages may still be important enough for others to engage in parallel programming efforts. There are no real benefits for you.

- Put the source code into the public domain

To open all advantages of source code access to everybody, you could explicitly give up on the copyright, and put your work in the public domain. This has the potential of greatly increasing 
the use of your programming effort, and eliminates the motivation for any parallel effort. Some people do this, simply because they like to see a wide adoption of their contribution. There may be some secondary economic advantages, Raymond (1999), but also unwanted side effects. Anybody may legally take your code and build a proprietary computer programme on it, or integrate parts of it into existing proprietary software.

- Release the source code under relaxed copyright

Most commercial software licenses impose further restrictions, for which an agreement is necessary between licensee and licenser. But it is equally possible to formulate a license that states additional freedoms, relaxing the protection of the copyright, in exchange of specific obligations by the licensee. The license can state itself to be void in case any of the obligations are breached, which effectively turns the act into a violation of copyright law. For someone that does not accept the license and the obligations, the work is automatically protected by ordinary copyright. For people who do accept the license, no signed agreement needs to exist for the obligations to be binding. This is the mechanism that makes Free/Libre and Open Source Software successful.

\section{Definition of Terms}

The English language has difficulties to put a name on software that is licenced under relaxed copyright. The term "Free Software" has been used for many years now, and is often associated with Richard Stallman. In 1984, Stallman launched the GNU project (www.gnu.org) to develop a free operating system. GNU is still an important part of the now widely distributed free operating system that is informally called Linux. In 1985, Stallman founded the Free Software Foundation (FSF), www.fsf.org, to promote computer users' rights to use, study, copy, modify, and redistribute computer programs. Both Stallman and his projects still play an important role in the Free Software movement today.

However, there is an ambiguity in the word "free" because it has different meanings when used as in "free beer" and as in "free speech". In practice, both meanings often apply to Free Software, but the price of Free Software is not really important. You may sell Free Software if you can. The latter meaning of the word "free" is about freedom and liberty, which really is the essence of Free Software.

Unfortunately, most people think of economics when they think of something free, and you always need to disambiguate the term when you speak of Free Software. It is possible that therefore "Free Software" does not appeal to business people. This has been considered to be a problem, which has motivated an other movement, the Open Source Initiative, www.opensource.org, in 1998. The Open Source Initiative (OSI) is a marketing program for Free Software, and aims to advocate it on solid pragmatic grounds. It has registered the term "Open Source" as a trade mark, and popularised it as a synonym for "Free Software". OSI certifies software as Open Source, and carries a list of approved licenses (amounting to almost 60 licenses at the time of this writing).

Although the term "Open Source" is probably the most widely used term today, it is not without problems. Some people feel that it does not cover the essence (i.e. freedom) well enough, Stallman (2002). Indeed, sometimes software is claimed to be Open Source, whereas it really only is published source code, without the copyright having been relaxed. As a matter of fact, OSI clarifies that "Open Source doesn't just mean access to the source code" and gives a detailed definition of the term, consisting of ten criteria that software must comply with before it may be called Open Source. These criteria differ slightly from the ones that the FSF practices; some of the license restrictions that the OSI accepts for Open Source are too restrictive in the eyes of the FSF, www.gnu.org/philosophy/categories.html.

During a translation of the English GNU General Public License (GPL) into Spanish, it appeared that Roman languages do not suffer the ambiguity problem, González-Barahona (2004). The word "free" with respect to price is translated into Spanish as "gratis", and "free" with respect to liberty is translated as "libre". Because of the problems with the terms "Free Software" and "Open Source", 
some people have started to use the term "Libre Software", even though this is a mix of languages. This term is gaining popularity, notably in official circles in Europe. For example, in 1999, the Information Society Directorate General of the European Commission initiated the European Working Group on Libre Software, eu.conecta.it.

In 2002, the acronym FLOSS was introduced, in a survey and study commissioned by the European Commission, Ghosh and Glott (2002), to cover all of Free/Libre and Open Source Software at once.

Both Free Software and Open Source software recognise source code that has been put in the public domain, because everyone is free to use such software in any way they like. Software that is guaranteed to be FLOSS in all its derivative variants, by means of a clause that makes derivative works inherit the licence of the original and the requirement that source code always must be made available, is often identified with the term "Copyleft" (as opposed to "Copyright"). In general, the advantages of FLOSS are considered to be highest under a Copyleft license.

\section{$2.1 \quad$ FLOSS Licences}

For an exhaustive list of officially recognised Free/Libre and Open Source Software licenses the reader is referred to the sites of the FSF and OSI, www.gnu.org/licenses/license-list.html and www.opensource.org/licenses/. However, the important question is not whether any particular license is approved by either organisation. The important question is whether a piece of software that you are interested in is licensed under terms that you can accept, and for this you should always consult the actual license text that follows with the software. The other important question is which license to choose or construct when you consider to write FLOSS or consider to release existing work as FLOSS. To help answer the latter question, both organisations have put together guides and "HOWTOs", www.fsf.org/licensing and www.catb.org/ esr/Licensing-HOWTO.html.

For completeness however, we briefly explain the licenses that are used for relevant FLOSS as listed in section 4. Both the MIT and BSD licences allow almost everything, except removal of the license statement and copyright notice. They also disclaim warranty and liability, and the BSD licence adds a non-endorsement clause. The following licenses are all Copyleft. The most widely used license is the GNU GPL license, or General Public Licence. Proprietary software can not include or even link with GPLed code. The QPL, or Qt Public License, is rarely used, and is comparable but incompatible with the GPL. The GNU LGPL, or Lesser General Public Licence, is similar to the GPL but allows LGPLed libraries to be linked to by proprietary software. The wxWindows Library Licence is identical to the LGPL, however with an exception that states additional freedoms for binary distribution.

\section{The Case for FLOSS}

The OSI helps you weigh the advantages and disadvantages between an open development model and a closed development model. Here it is often assumed that you are able to extract direct revenue out of your proprietary software. The OSI explains that even if this is the case, the pay-off of converting to FLOSS can be higher than the pay-off of remaining in proprietary mode. However, we will proceed with the simpler assumption that you are the only user of your in-house developed software.

There are three main advantages of writing FLOSS as opposed to writing software in-house:

\section{Peer Review}

The peer review helps improving the quality and feature-richness of your software. Because the software is available freely, a community of "beta testers" (your users) will connect with you and help you find bugs. And because they have access to the code and are allowed to play with it, they will send you bug fixes if they can, in exchange for just gratification and recognition. For the same reasons, you may get sent patches that add new features to your software.

2. Free Building Blocks

Because you are writing FLOSS, you are free to build on existing FLOSS linking with libraries 
that exist for different purposes, and thereby use the peer reviewed work of others instead of reinventing the wheel yourself. Also, you may find an existing project, either fully functional or in early stages of development, that you can extend to make it satisfy your requirements. In these ways you can reach your goal much sooner than when doing it all alone.

The risk of depending on third party code that exists in a proprietary setting, namely that the software may disappear because of a business situation with the vendor, is non-existent with FLOSS. If a piece of FLOSS gets dropped by its originators, you are free to pick it up and maintain and evolve it yourself. Therefore, a FLOSS project will thrive as long as there are people interested in it. The same advantage applies to the accessibility of data files. The information in old data files, written in a proprietary format with a proprietary program that is not available anymore, is inaccessible and effectively lost. But if you have the source code of the application that wrote the data file, you can understand the format and extract the information.

3. You work in an organisational mode that is arguably the most effective for the management of complex systems, Raymond (1999)

If you are still reluctant to publish work from which your competitor may benefit, you may consider the following. Even when your nearest competitor starts using your software intensively in a FLOSS framework, he will make improvements and he will have to contribute them back to you and make your software better. Therefore, it is important to be the first to embark in FLOSS mode, because it gives you more control of the situation. You still own the software, and it is you who decides where to take it. Raymond (1999) also says about this: "[T]here's a serious opportunity risk in waiting too long: you could get scooped by a competitor going open-source in the same market niche. The reason this is a serious issue is that both the pool of users and the pool of talent available to be recruited into open-source cooperation for any given product category is limited, and recruitment tends to stick. If two producers are the first and second to open-source competing code of roughly equal function, the first is likely to attract the most users and the most and best-motivated co-developers; the second will have to take leavings."

If you are a scientist, commercial competition may not be so much of an issue, and with that the choice for FLOSS should be easy. FLOSS poses great opportunities for learning, and universities are encouraged to take the lead in developing FLOSS, also for maritime applications.

Before jumping on the FLOSS bandwagon in all enthusiasm, be sure to be prepared for the rules of the game. FLOSS development is a voluntary community effort, and people skills are essential when leading one. This is especially the case because the Internet is a poor medium for social communication. In order to make FLOSS development work for you, you need to understand the process well. Again, Raymond (1999) can be a source of insight.

\section{FLOSS Software}

Examples of existing Free/Libre and Open Source Software are given in six categories: geometric modelling, visualisation, numerics, finite element method, computational fluid dynamics, and graphical user interfaces. The information about each project also includes the latest version and release date at the time of this writing, which is an indication of the degree of maturity and the developer activity respectively. The list is not exhaustive.

\subsection{Geometric Modelling}

Blender is a $3 \mathrm{D}$ graphics creation suite with a focus on the entertainment industry. Its modelling capabilities include polygon meshes, NURBS surfaces, Bézier and B-spline curves, meta-balls, and "Smooth proxy" style Catmull-Clark subdivision surfaces with optimal iso-lines display and sharpness editing. It supports Python scripting for the creation of custom tools. 


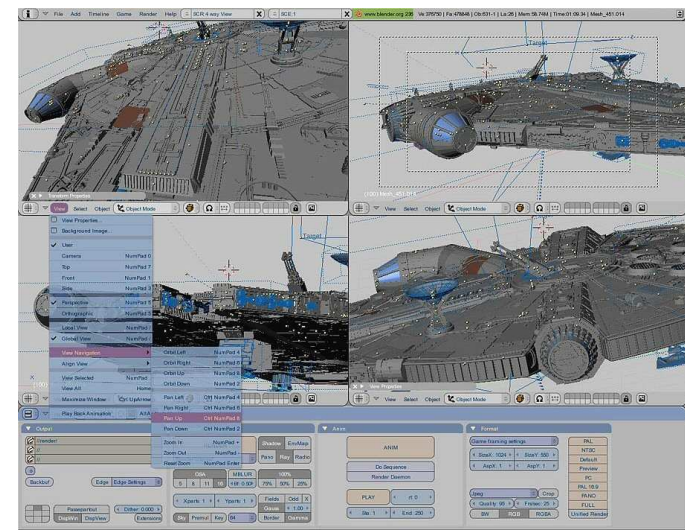

\author{
Homepage: www.blender.org \\ Latest version: $2.36,22$ Dec 2004 \\ License: GPL 2 \\ Language: $\quad \mathrm{C}, \mathrm{C}++$, Python \\ Platforms: Windows, Mac OS X, Linux, \\ Solaris, Irix, FreeBSD
}

Fig.1: The Blender modeller

Wings 3D is a polygon mesh modeller with a user interface that is easy to use for both beginners and advanced users. Wings 3D uses subdivision surfaces rather than NURBS surfaces.

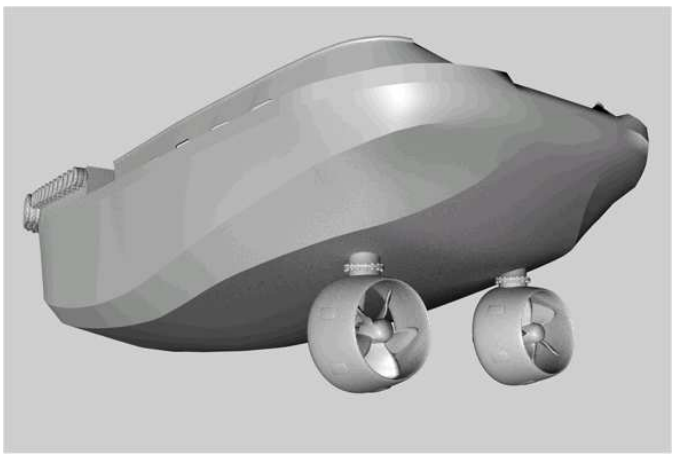

$$
\begin{aligned}
\text { Homepage: } & \text { www.wings3d.com } \\
\text { Latest version: } & 0.98 .26 \mathrm{~b}, 16 \text { Dec } 2004 \\
\text { License: } & \text { BSD License } \\
\text { Language: } & \text { Erlang } \\
\text { Platforms: } & \text { Windows, Mac OS X, Linux, } \\
& \text { other Unix systems }
\end{aligned}
$$

(Image source:

www.naval-architecture.co.uk/phpbb/

viewtopic $\cdot$ php?t=12)

Fig.2: The Wings 3D modeller

Open CASCADE is an industrial Open Source alternative to proprietary 3D modelling kernels, a library that includes components for 3D surface and solid modelling, visualisation, data exchange and rapid application development. Open CASCADE Technology can be best applied in development of numerical simulation software including CAD/CAM/CAE, AEC and GIS, as well as PDM applications. The technology exists since the mid 1990s and has been used by numerous commercial clients.
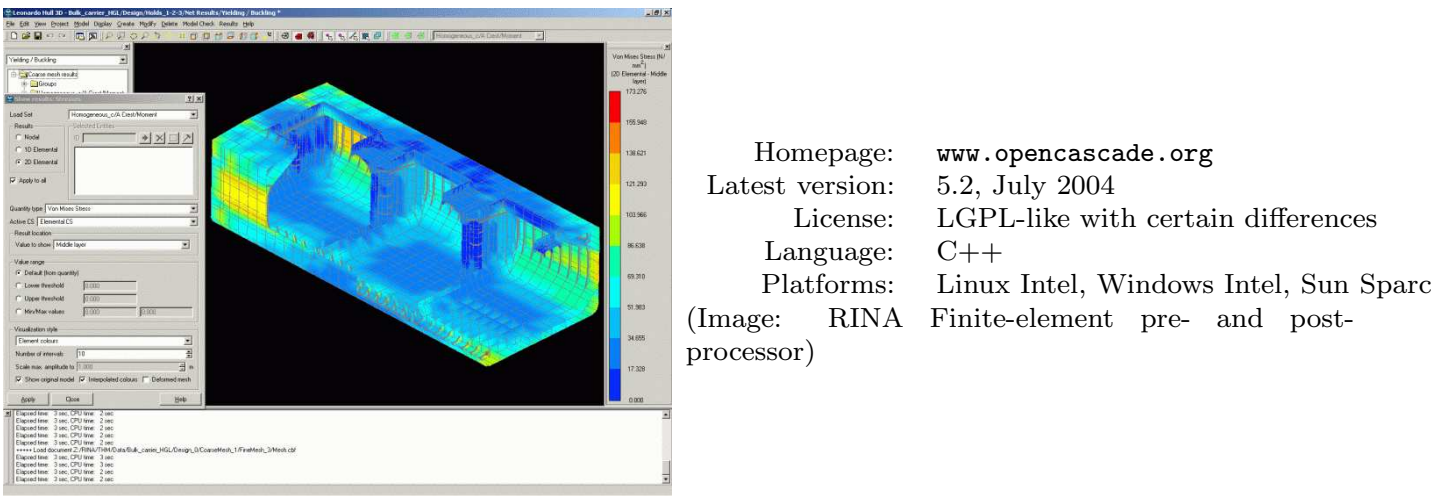

Fig.3: The OpenCASCADE surface and solid modelling kernel

FreeCAD will be a general purpose 3D CAD system based on OpenCasCade. FreeCAD will aim directly at mechanical engineering, product design and related features (like CatiaV4 and V5, and SolidWorks). It will be a feature-based parametric modeller. Scripting is supported through Python. 


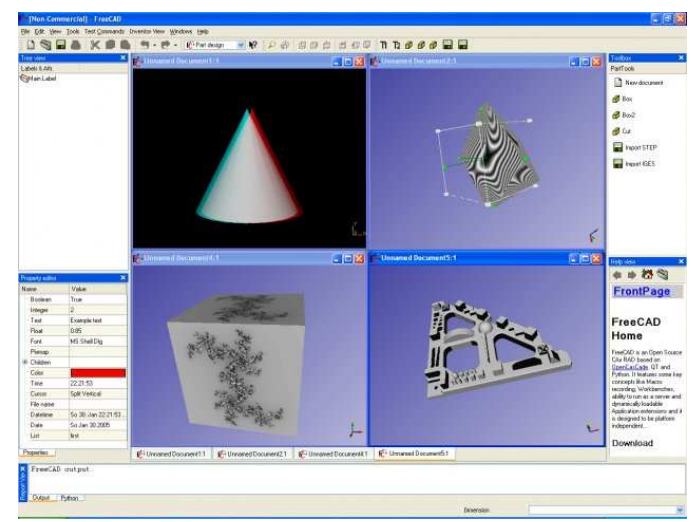

$\begin{aligned} \text { Homepage: } & \text { free-cad.sourceforge.net } \\ \text { Latest version: } & 0.1 \mathrm{~B} 107 \\ \text { License: } & \text { GPL, LGPL } \\ \text { Language: } & \text { C++, Python } \\ \text { Platforms: } & \text { Linux, Windows }\end{aligned}$

Fig.4: The FreeCAD system

BRL-CAD is a powerful constructive solid geometry (CSG) solid modelling system that includes an interactive geometry editor, ray tracing support for rendering and geometric analysis, network distributed frame-buffer support, and image and signal-processing tools.

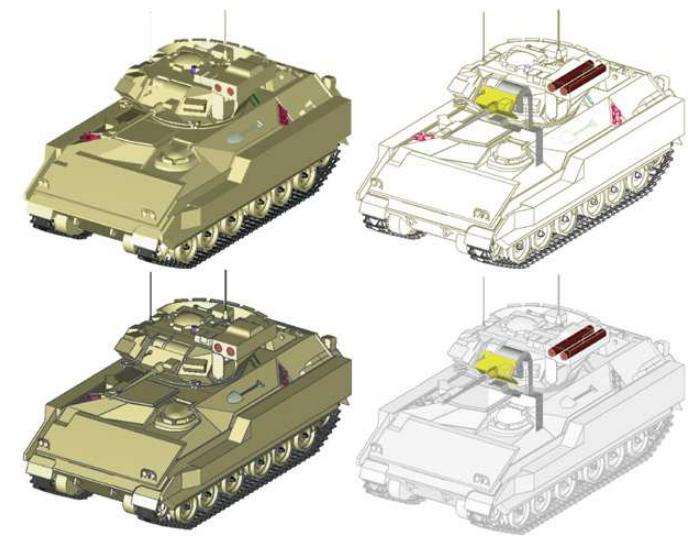

\author{
Homepage: brlcad.sourceforge.net \\ Latest version: 7.0.2, 6 Jan 2005 \\ License: BSD License, GPL, LGPL \\ Language: $\quad \mathrm{C}, \mathrm{C}++$, Java, PHP, Tcl, Unix Shell \\ Platforms: Windows and all BSD and POSIX platforms, incl. Linux, \\ Mac OS X, Solaris, Irix etc.
}

Fig.5: The BRL-CAD solid modelling system

VARKON can be used as a traditional CAD system with drafting, modelling and visualisation, but the real power of VARKON is in parametric modelling and CAD applications development. VARKON includes interactive parametric modelling in 2D or 3D but also the unique MBS programming language integrated in the graphical environment. VARKON is designed to be modified and extended with knowledge and functionality specific to a certain product or problem. It is not a true solid modeller.
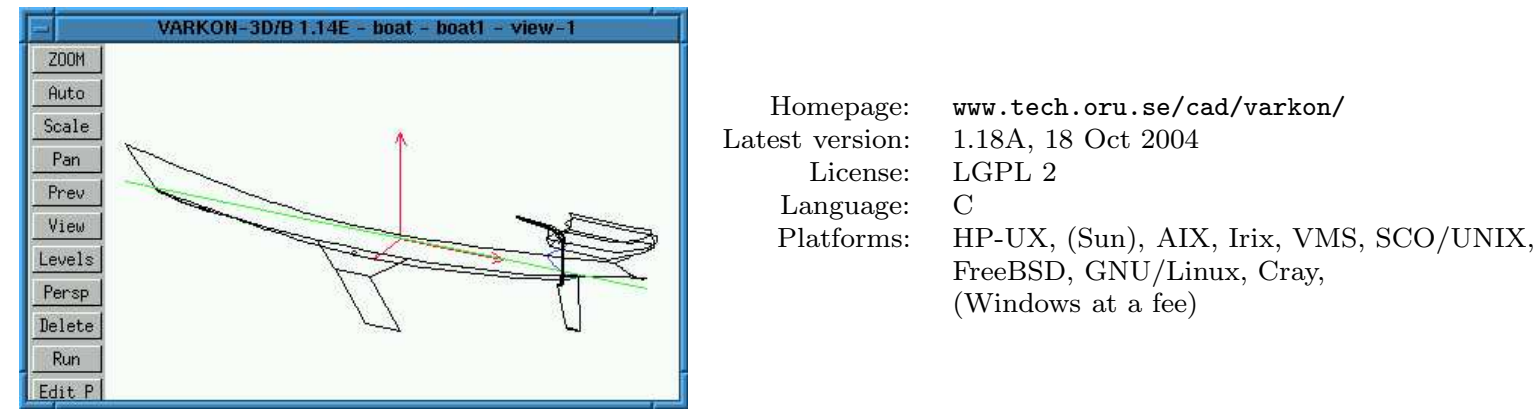

Fig.6: The Varkon CAD system

Sailcut CAD is a sail design and plotting software. It allows you to design and visualise your own sail and compute the accurate development of all panels in flat sheets. 


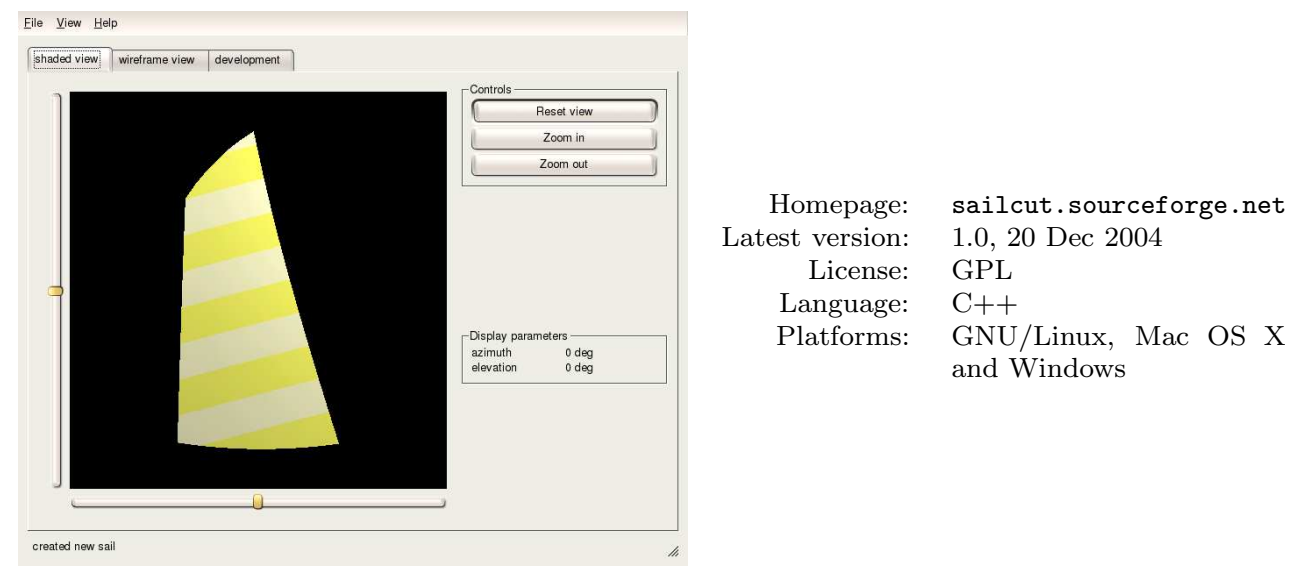

Fig.7: The Sailcut CAD sail design and plotting software.

SketchBoard is a sketch oriented CAD software. It is a tool for designers to develop their design by sketching and modelling in 3D. It has a system that helps converting the sketch into a polygon.

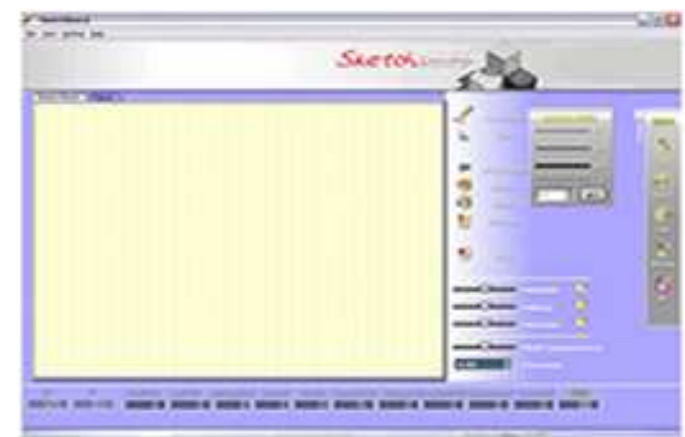

$\begin{aligned} \text { Homepage: } & \text { sketchboard.sourceforge.net } \\ \text { Latest version: } & 1.22,22 \text { Apr } 2004 \\ \text { License: } & \text { GPL } \\ \text { Language: } & \text { C }++ \\ \text { Platforms: } & \text { Windows }\end{aligned}$

Fig.8: The SketchBoard CAD software

\subsection{Visualisation}

Coin3D is a set of libraries used for creating 3D graphics applications. Coin3D is fully compatible with SGI Open Inventor 2.1, the de facto standard for 3D visualisation and visual simulation software in the scientific and engineering community. Additional features in Coin3D include VRML97 support, sound, 3D textures, and parallel rendering on multiple processors.
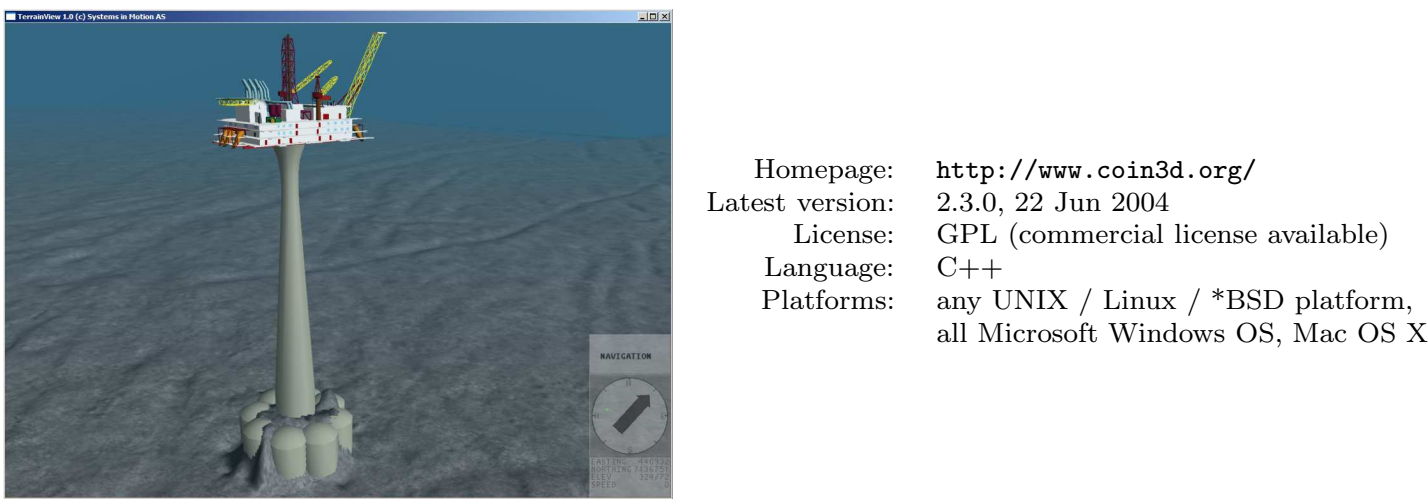

Fig.9: The Coin3D graphics library

ADMesh is a processor for repairing, transforming and merging triangulated solid meshes. It reads STL file format (used for rapid prototyping applications) and writes STL, VRML, OFF, and DXF files. 
(console application)

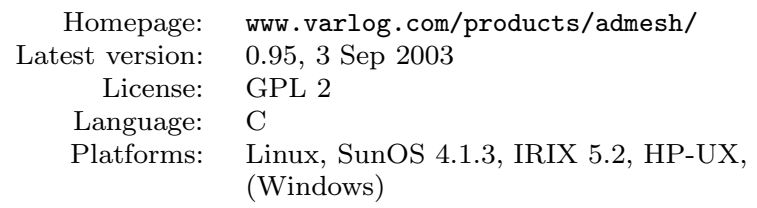

Fig.10: The ADMesh processor

Pixie is a photo-realistic renderer that uses a RenderMan-like interface. Features include programmable shading, motion blur, depth of field, ray-tracing, scan-line rendering, occlusion culling, global illumination, caustics, etc.

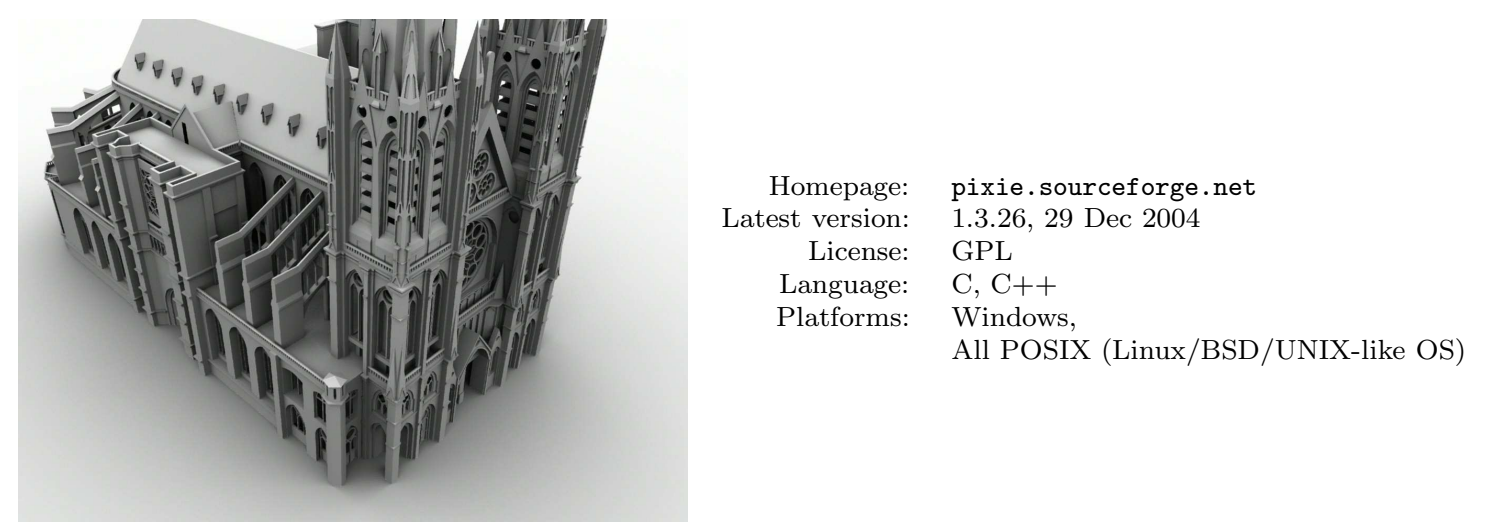

Fig.11: The Pixie renderer

YafRay is a powerful ray-tracer. It enables you to create fantastic images and animations of a photo realistic quality. Its API (Application Programming Interface) and its modular structure allow to develop rendering plug-ins, making it possible to use YafRay from any program or 3D suite. At the time of this writing, suites as Blender, Wing3D or Aztec take advantage of this feature.

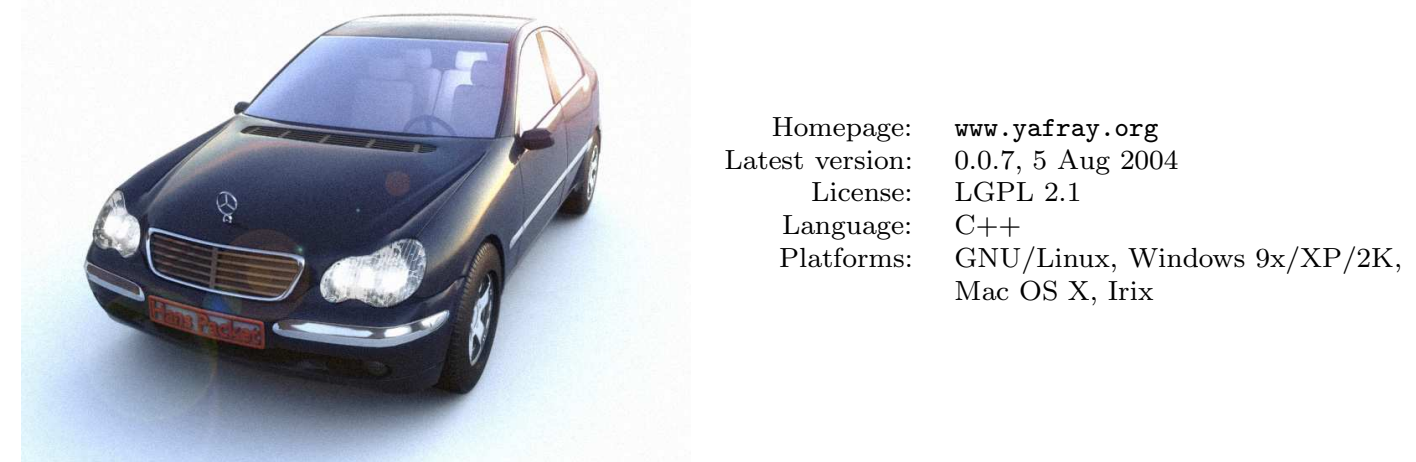

Fig.12: The YafRay ray-tracer

GeomView is an interactive 3D viewing program for Unix. It can be used as a stand-alone viewer for static objects or as a display engine for other programs which produce dynamically changing geometry. It can display objects described in a variety of file formats. 


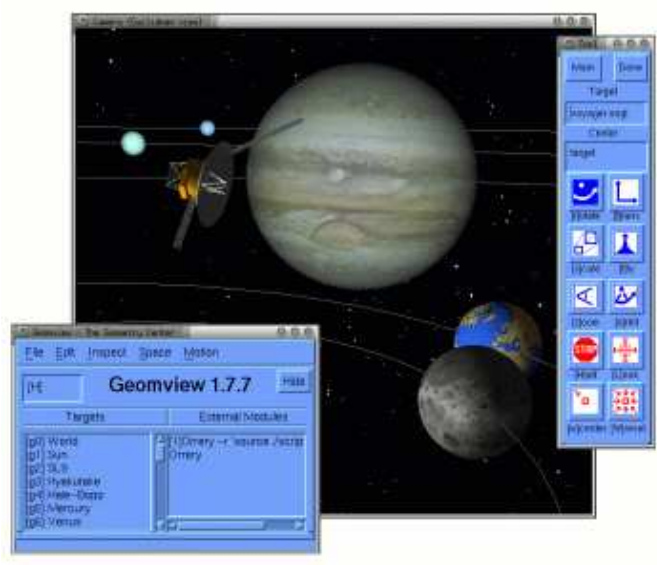

\author{
Homepage: www.geomview.org \\ Latest version: 1.8.1, 25 Mar 2001 \\ License: LGPL 2.1 \\ Language: $\mathrm{C}, \mathrm{C}++$ \\ Platforms: Unix-like OS incl. GNU/Linux, Solaris, \\ IRIX, AIX
}

Fig.13: The GeomView viewer

MayaVi is a free, easy to use scientific data visualiser.
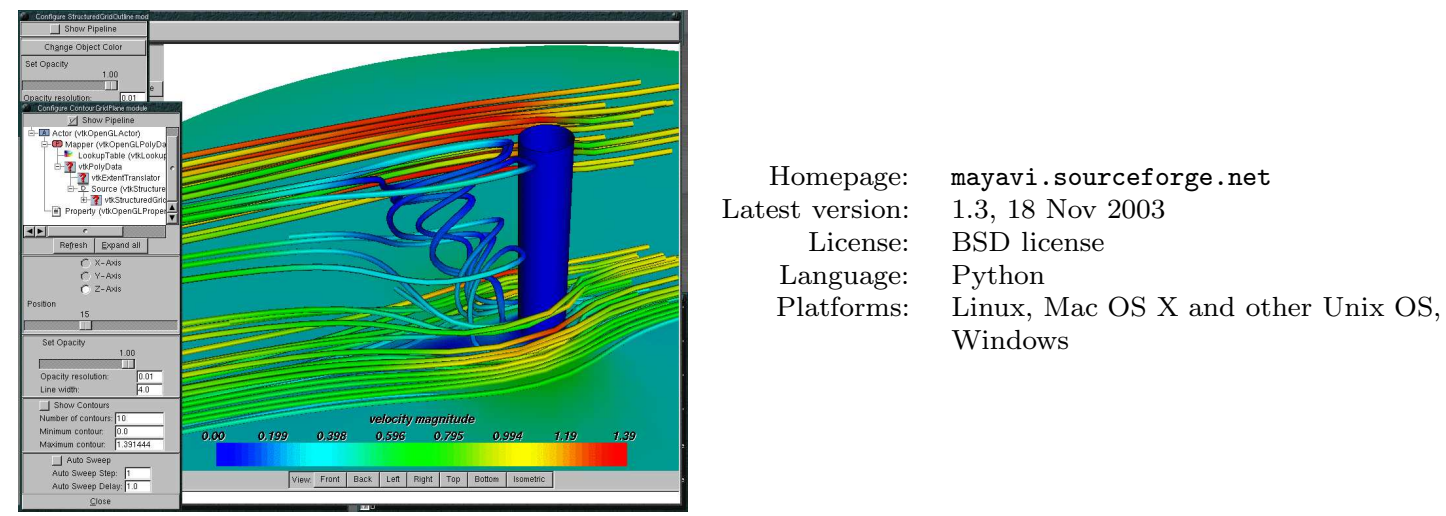

Fig.14: The MayaVi data visualiser

\title{
4.3 Numerics
}

Beyond the software referenced below, there are many other powerful numerics libraries. Many of them are listed at www.oonumerics.org/oon.

GNU Octave is a high-level language, primarily intended for numerical computations. It provides a convenient command line interface for solving linear and nonlinear problems numerically, and for performing other numerical experiments using a language that is mostly compatible with Matlab. It may also be used as a batch-oriented language. Octave has extensive tools for solving common numerical linear algebra problems, finding the roots of nonlinear equations, integrating ordinary functions, manipulating polynomials, and integrating ordinary differential and differential-algebraic equations. It is easily extensible and customisable via user-defined functions written in Octave's own language, or using dynamically loaded modules written in $\mathrm{C}++, \mathrm{C}$, Fortran, or other languages.

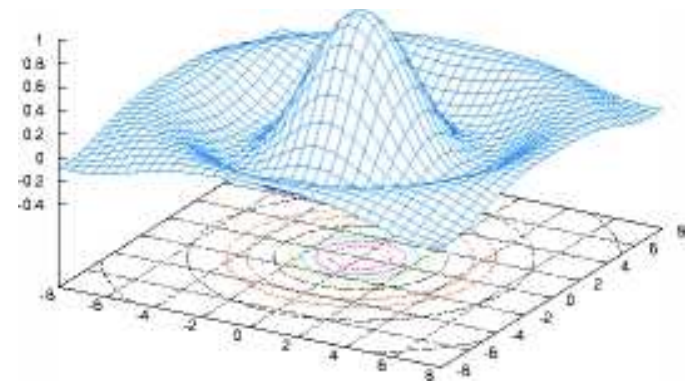

Homepage: www.octave.org, octave.sourceforge.net

Latest version: 2.9.0, 15 Mar 2005

License: GPL 2

Language: $\mathrm{C}, \mathrm{C}++$, Fortran

Platforms: Linux, Mac OS X, Windows

Fig.15: The Octave language (mostly Matlab compatible) 
FreeMat is a free environment for rapid engineering and scientific prototyping and data processing. It is similar to proprietary systems such as MATLAB from Mathworks, and IDL from Research Systems. FreeMat includes several novel features such as a code-less interface to external C/C++/FORTRAN code, parallel/distributed algorithm development (via MPI), and plotting and visualisation capabilities.

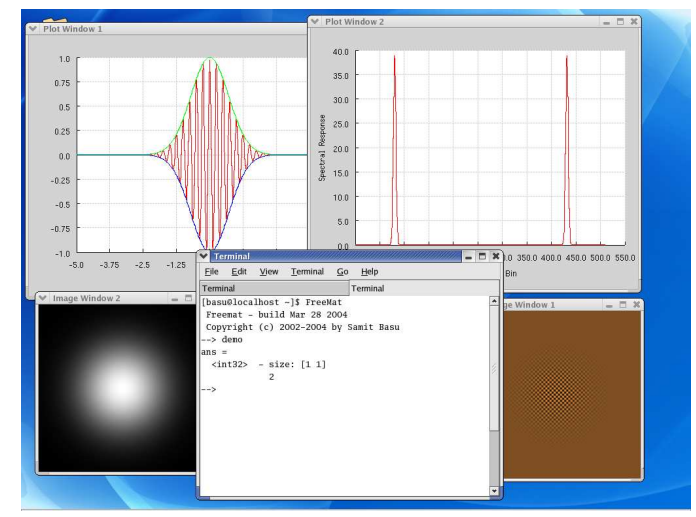

\author{
Homepage: freemat.sourceforge.net \\ Latest version: $1.09,27$ Oct 2004 \\ License: MIT-type \\ Language: $\mathrm{C}, \mathrm{C}++$, FORTRAN \\ Platforms: Linux, Windows and Mac OS X
}

Fig.16: FreeMat, an alternative to Matlab

Maxima is a fairly complete computer algebra system written in Lisp with an emphasis on symbolic computation. Its abilities include symbolic integration, 3D plotting, and an ODE solver.

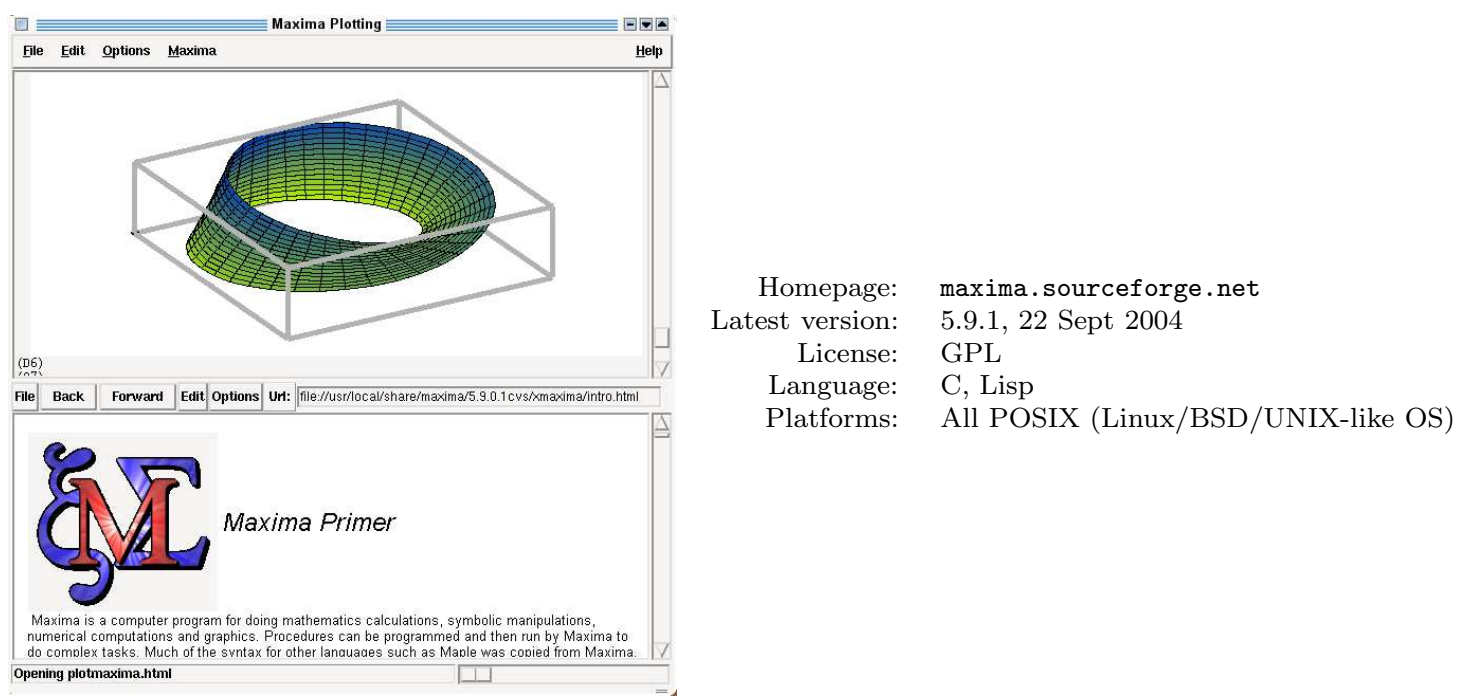

Fig.17: The Maxima computer algebra system

The ATLAS (Automatically Tuned Linear Algebra Software) project is an ongoing research effort focusing on applying empirical techniques in order to provide portable performance. At present, it provides $\mathrm{C}$ and Fortran77 interfaces to a portably efficient BLAS implementation, as well as a few routines from LAPACK.

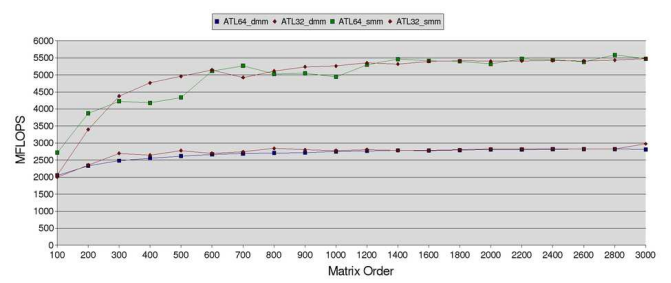

\author{
Homepage: math-atlas.sourceforge.net \\ Latest version: $3.7 .8,23$ Jul 2004 \\ License: BSD License \\ Language: C, Fortran77 \\ Platforms: Linux and other Unix OS, Windows
}

Fig.18: The Automatically Tuned Linear Algebra Software

\title{
4.4 FEM
}


Gmsh is an automatic 3D finite element grid generator (primarily Delaunay) with a build-in CAD engine and post-processor. Its design goal is to provide a simple meshing tool for academic problems with parametric input and advanced visualisation capabilities.

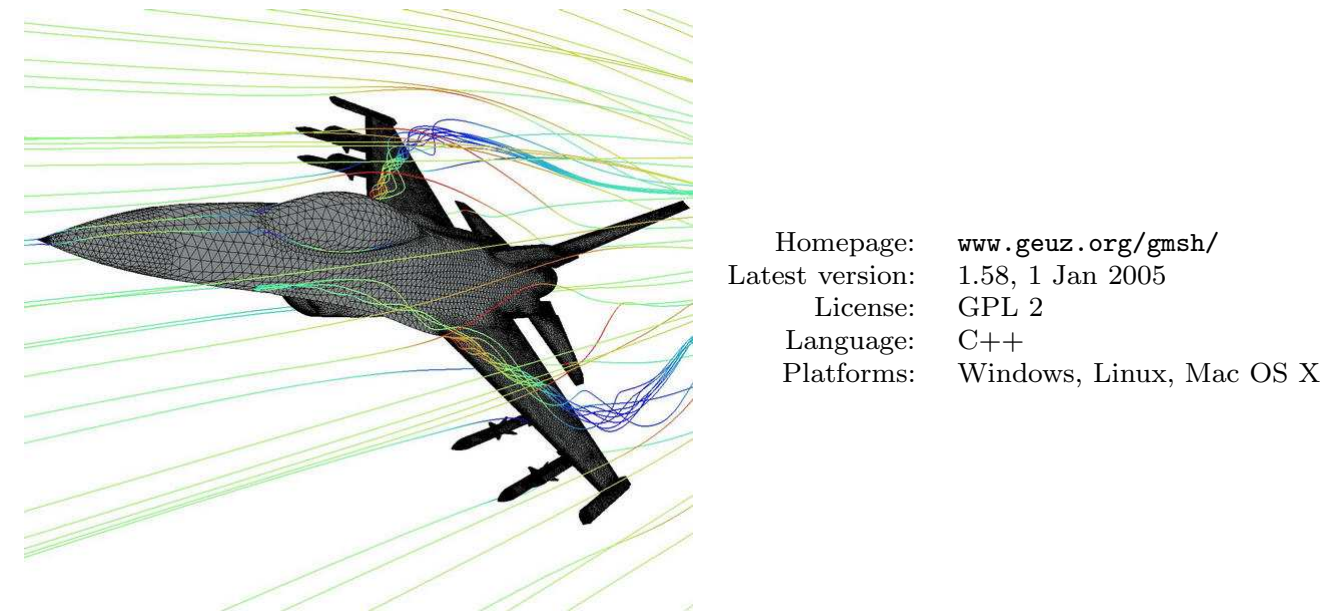

Fig.19: The Gmsh mesh generator

NETGEN is an automatic 3D tetrahedral mesh generator. It accepts input from constructive solid geometry (CSG) or boundary representation (BRep) from STL file format. The connection to a geometry kernel allows the handling of IGES and STEP files. NETGEN contains modules for mesh optimisation and hierarchical mesh refinement. NETGEN works together with NGSolve.
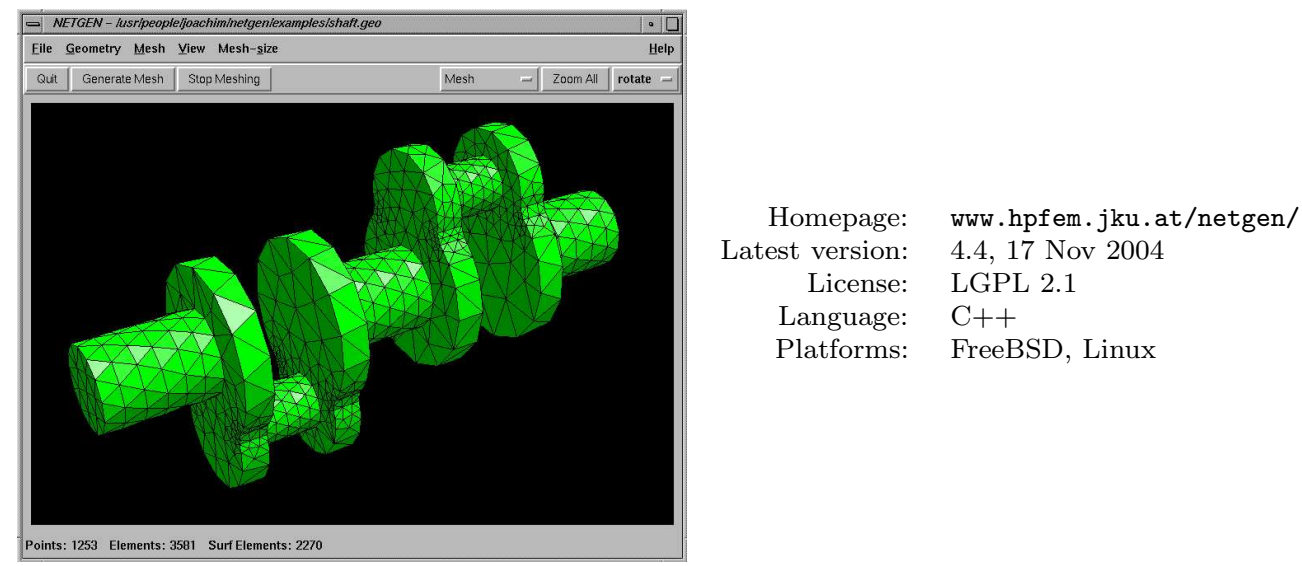

Fig.20: The NETGEN mesh generator

NGSolve is a general purpose 3D finite element solver, supporting boundary value problems, initialboundary value problems and Eigenvalue problems for the available types of equations, namely scalar (heat flow), elasticity, and magnetic field. NGSolve performs adaptive mesh refinement, the matrix equations are solved by optimal order multi-grid methods. Works together with NETGEN. 

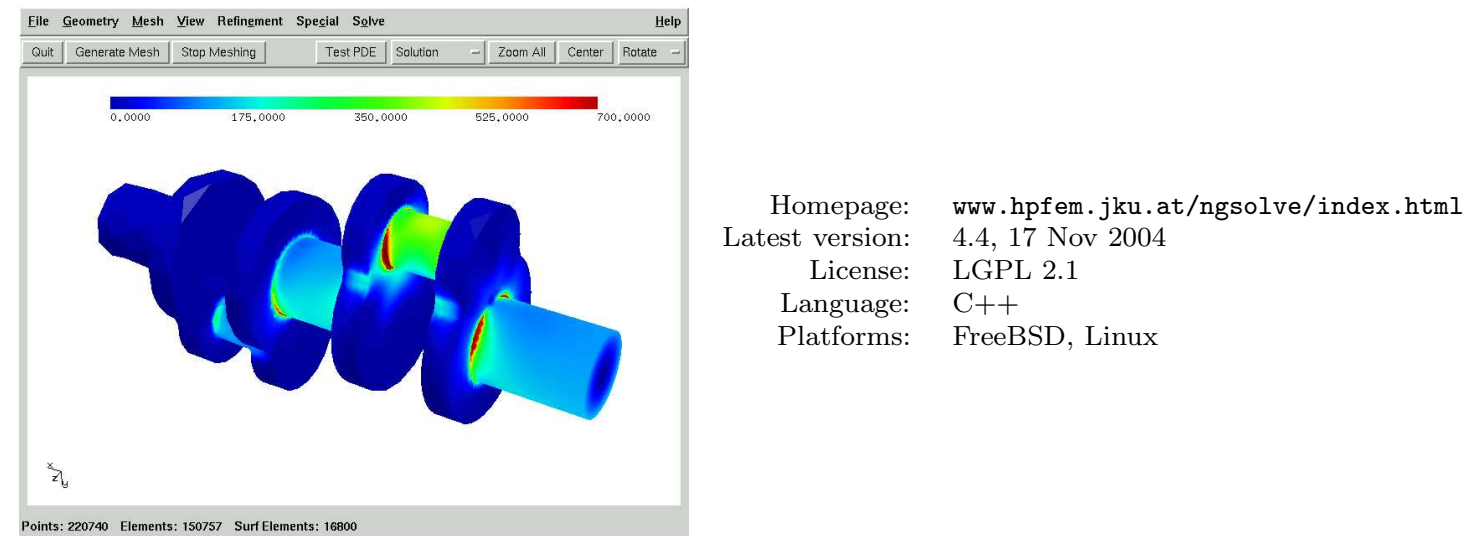

Fig.21: The NGSolve solver

CalculiX is a 3D structural FEM program. CalculiX allows to build models, calculated and postprocessed. The pre- and post-processor is an interactive 3D-tool using the OpenGL API. The solver allows linear and non-linear calculations. Static, dynamic and thermal solutions are available. Both programs can be used independently. Because the solver employs the Abaqus input format, it is possible to use proprietary pre-processors as well. In turn, the pre-processor is able to write mesh related data for Nastran, Abaqus and Ansys and for the free CFD code DUNS. A VDA CAD interface is available.

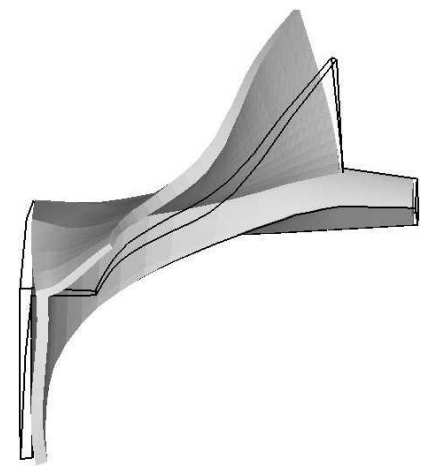

$\begin{aligned} \text { Homepage: } & \text { www.calculix.de } \\ \text { Latest version: } & 1.2,25 \text { Jul } 2004 \\ \text { License: } & \text { GPL } 2 \\ \text { Language: } & \text { Fortran77, C } \\ \text { Platforms: } & \text { Unix, including Linux and Irix }\end{aligned}$

Fig.22: The CalculiX solver

SLFFEA (San Le's Free Finite Element Analysis) is a package of scientific software and graphical user interfaces for use in (non-linear) finite element analysis.
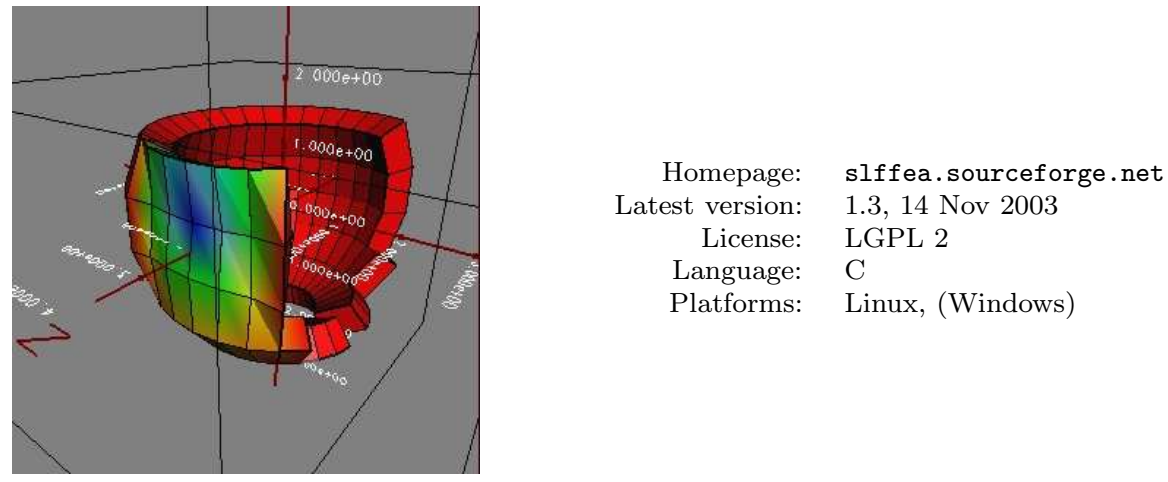

Fig.23: San Le's Free Finite Element Analysis

TOCHNOG is a feature-rich FEM program. Among the FEM models supported are: differential equations (materials), convection-diffusion equations, Stokes and Navier-Stokes (fluids), elasticity (isotropy and transverse isotropy), plasticity (Von-Mises, Mohr-Coulomb, etc.; plastic surfaces can be arbitrarily combined). Residues in equations and error estimates for all data can be printed or plotted using gnuplot/plotmtv, CalculiX or gmsh. 


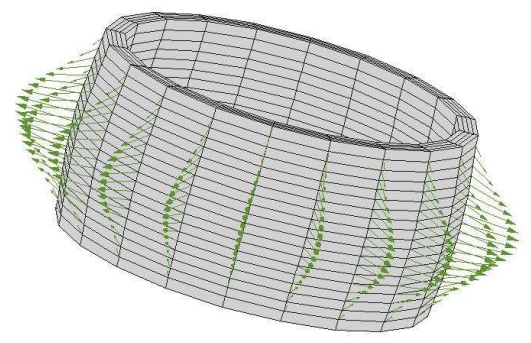

$\begin{aligned} \text { Homepage: } & \text { tochnog.sourceforge.net } \\ \text { Latest version: } & 26 \text { Nov } 2001 \\ \text { License: } & \text { GPL } 2 \\ \text { Language: } & \text { C++ } \\ \text { Platforms: } & \text { POSIX (such as Linux, BSD, } \\ & \text { UNIX-like OSes) and Windows }\end{aligned}$

Fig.24: The TOCHNOG finite element program

OFELI (Object Finite Element LIbrary) is a library of finite element $\mathrm{C}++$ classes for multipurpose development of finite element software. It is intended for teaching, research, and industrial developments.
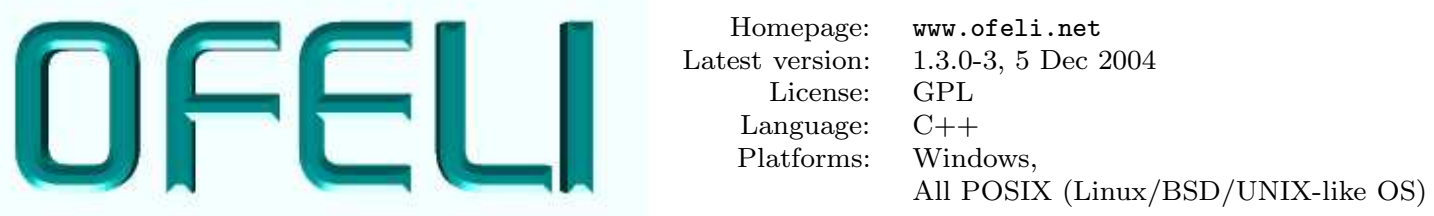

Fig.25: The Object Finite Element Library

\subsection{CFD}

FEATFLOW is a user-oriented, general-purpose subroutine system for the numerical solution of the incompressible Navier-Stokes equations in 2D or 3D. It supports stationary and non-stationary problems.
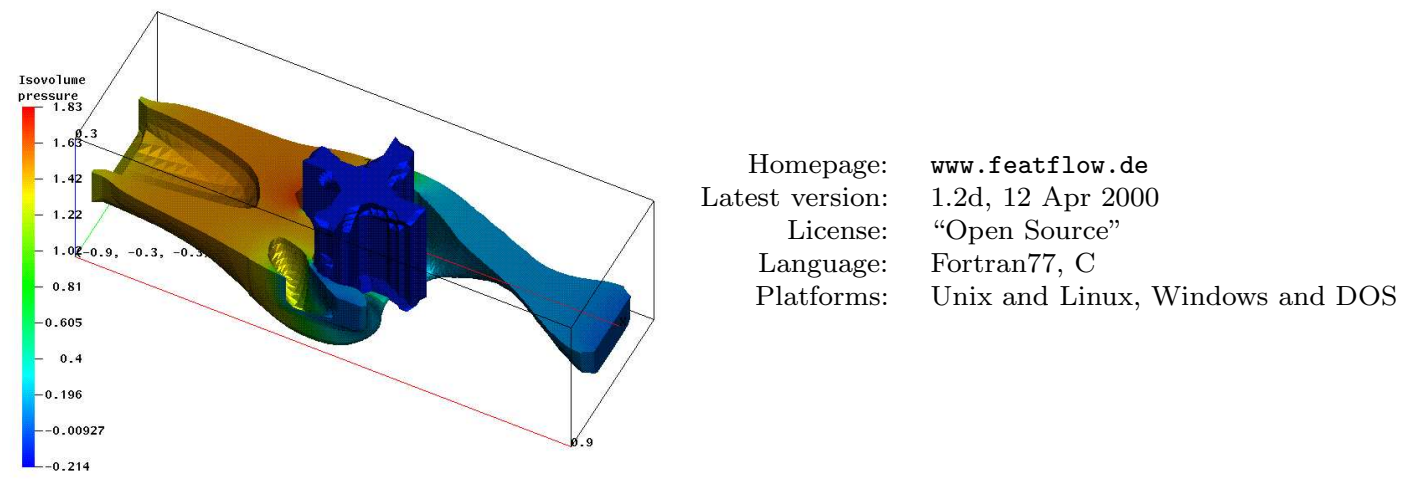

Fig.26: The FEATFLOW Navier-Stokes solver program and library

DUNS (Diagonalised Upwind Navier-Stokes) is a 2D/3D, structured, multi-block, multi-species, reacting, steady/unsteady, Navier Stokes fluid dynamics code with $k-\omega$ turbulence model.

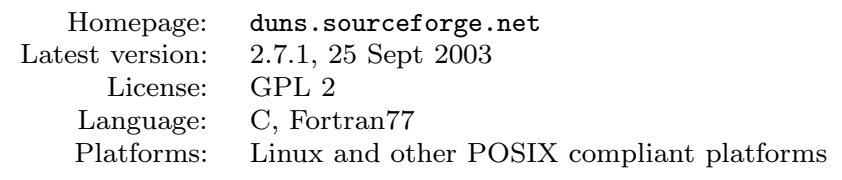

Fig.27: The DUNS code

OpenFlower (open FLOW solvER) is an open source CFD software written in $\mathrm{C}++$. It is mainly devoted to the resolution of the turbulent unsteady incompressible Navier-Stokes equations with a LES approach. It can deal with arbitrary complex 3D geometries with its finite volume approach. 


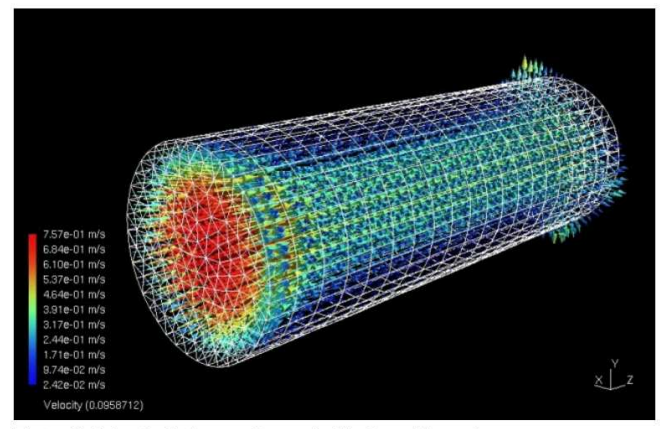

Homepage: openflower. sourceforge.net

Latest version: $0.3,11$ Oct 2004

License: GPL

Language: $\mathrm{C}++$

Platforms: POSIX, including Linux

First official calculation performed with OpenFlower

Velocity field inside a tube.

Fig.28: The OpenFlower CFD software

Gerris is a tool for generic numerical simulations of flows, possibly in geometrically complex geometries and including adaptive, multi-phase and interfacial flows capabilities.
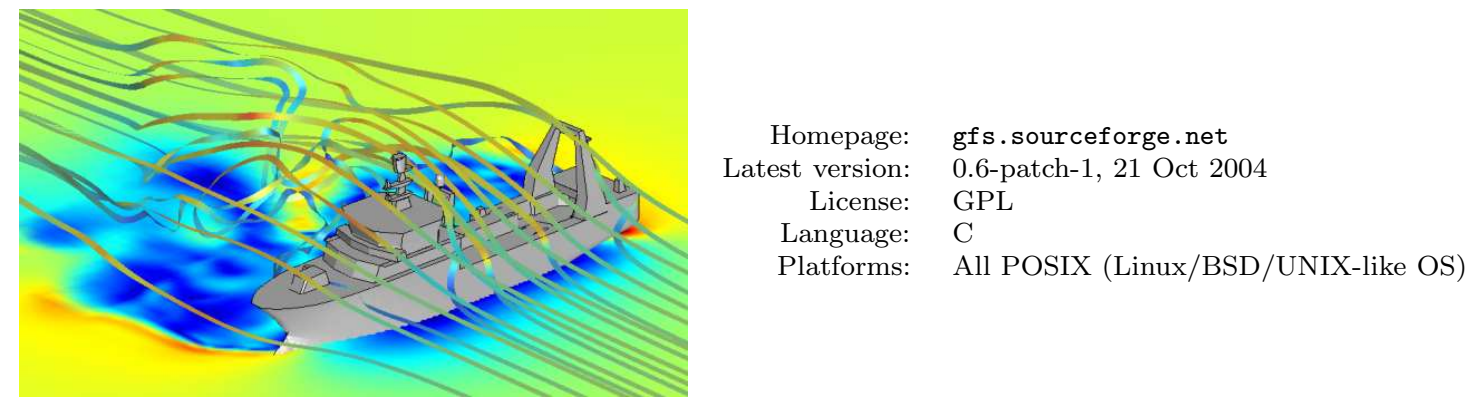

Fig.29: The Gerris Flow Solver

\subsection{GUI}

Qt intends to make cross-platform application programming intuitive, easy, and fun. Qt achieves this goal by abstracting low-level infrastructure functionality in the underlying window and operating systems, providing a coherent and logical interface that makes sense to programmers. The Qt API and tools are consistent across all supported platforms, enabling platform independent application development and deployment. Qt applications run natively, compiled from the same source code, on all supported platforms. Qt is the basis of the "K" Desktop Environment for Linux (KDE).
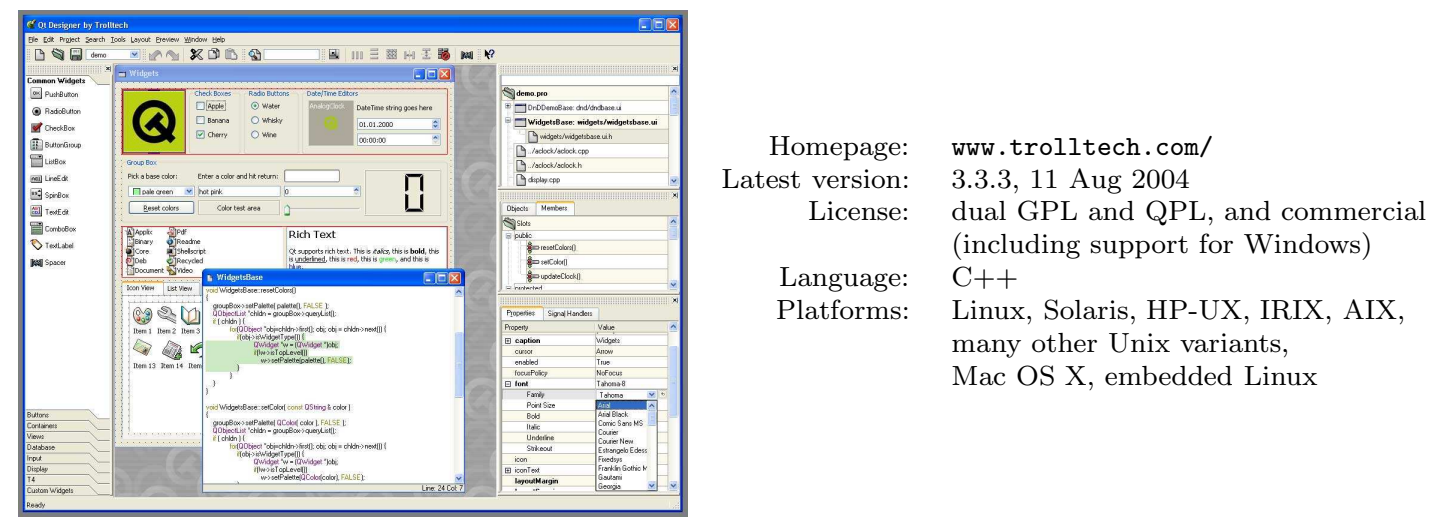

Fig.30: The Qt application framework

GTK + is a multi-platform toolkit for creating GUIs. Offering a complete set of widgets, GTK+ is suitable for projects ranging from small one-off projects to complete application suites. GTK+ has been designed from the ground up to support a range of languages, not only $\mathrm{C} / \mathrm{C}++$. Using $\mathrm{GTK}+$ from languages such as Perl and Python (especially in combination with the Glade GUI builder) 
provides an effective method of rapid application development. GTK+ is the basis of the "Gnome" desktop environment on Linux.

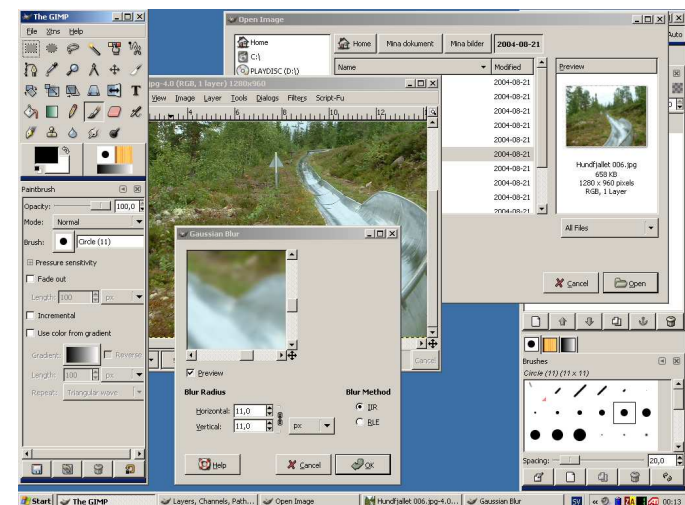

$$
\begin{aligned}
\text { Homepage: } & \text { www.gtk.org } \\
\text { Latest version: } & 2.6 .1,8 \text { Jan } 2005 \\
\text { License: } & \text { LGPL } \\
\text { Language: } & \text { C++ } \\
\text { Platforms: } & \text { GNU/Linux, BSD, So- } \\
& \text { laris, IRIX, HP-UX, AIX. } \\
& \text { There is a Windows port. }
\end{aligned}
$$

Fig.31: The GTK+ GUI library

wxWidgets gives you a single, easy-to-use API for writing GUI applications on multiple platforms, with native look and feel. On top of great GUI functionality, wxWidgets gives you: online help, network programming, streams, clipboard and drag and drop, multi-threading, image loading and saving in a variety of popular formats, database support, HTML viewing and printing etc.

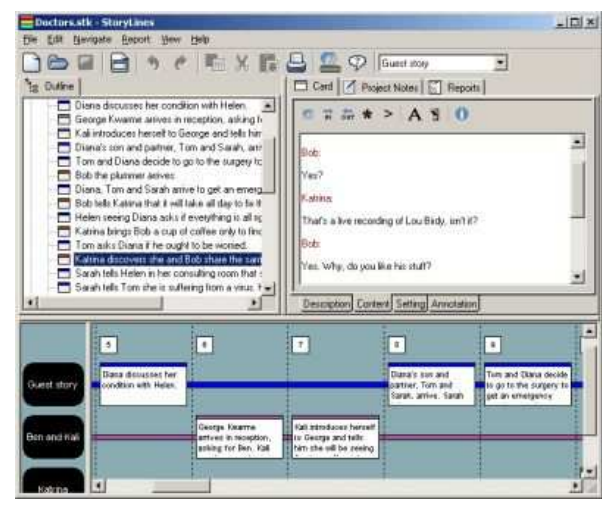

$\begin{array}{rll}\text { Homepage: } & \text { www.wxwidgets.org } \\ \text { Latest version: } & 2.5 .3,10 \text { Oct 2004 } \\ \text { License: } & \text { wxWindows Licence } & \text { (OSI certified) } \\ & \text { Language: }++ & \\ \text { Platforms: } & \text { Windows, } & \text { Unix, } \\ & \text { Mac OS X, MGL, OS } / 2\end{array}$

Fig.32: The wxWidgets GUI library

The Leonardo Library (LL) is a cross-platform, open-source C toolkit for program development. The library is light, well-documented, easy to learn, and covers a large number of functionalities, including graphic user interface, thread, I/O and memory management. Differently from other programming toolkits, the LL also includes components with fundamental algorithms and data structures. Graphic user interface components defined by the library preserve the look and feel of the target platform.

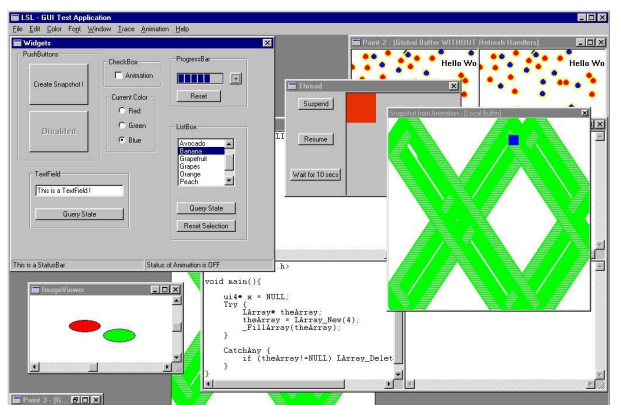

\author{
Homepage: www.leonardo-vm.org \\ Latest version: Qt-1.0.0b, 30 Nov 2003; \\ Win32-1.1.0b, 13 Feb 2004 \\ License: LGPL 2.1 \\ Language: $\mathrm{C}$ \\ Platforms: Linux, Windows
}

Fig.33: The Leonardo Library

FOX is a $\mathrm{C}++$ toolkit for easy and effective development of GUIs. It offers a wide collection of controls, and provides state of the art facilities such as drag and drop, selection, as well as OpenGL 
widgets for 3D graphical manipulation. FOX also implements icons, images, and user-convenience features such as status line help, and tool-tips. Tool-tips may even be used for 3D objects.
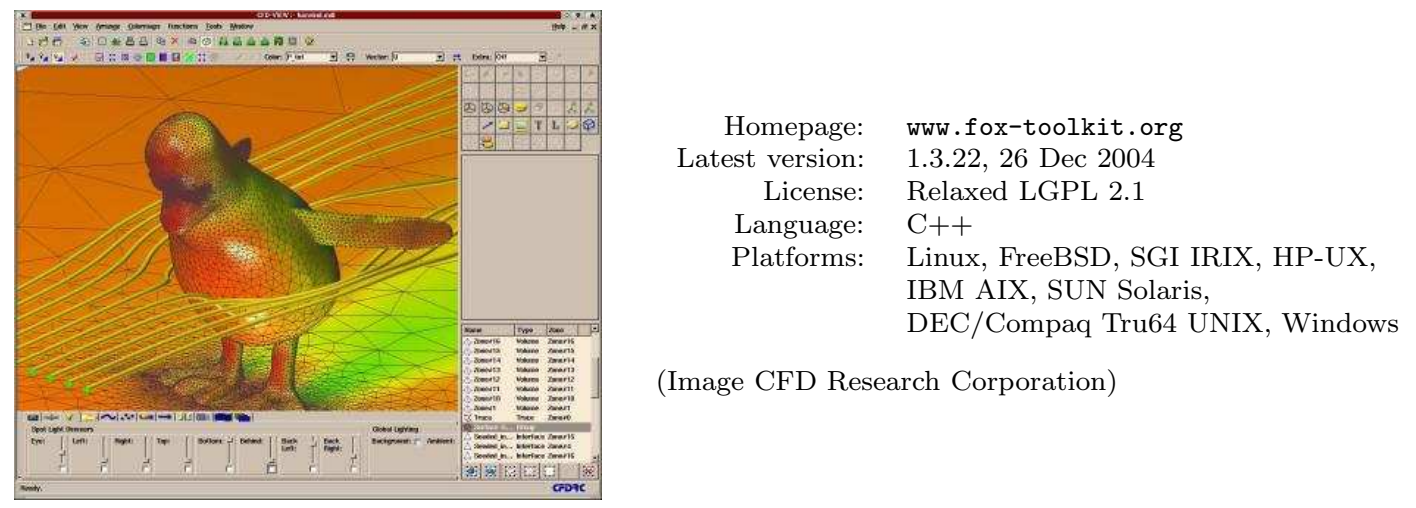

(Image CFD Research Corporation)

Fig.34: The FOX GUI toolkit

\section{Conclusion}

Free/Libre and Open Source Software (FLOSS) can be an attractive alternative to in-house developed software for ship design. The freedom to use existing FLOSS building blocks is an important motivator to get involved in FLOSS development. Therefore, this article gave references to selected FLOSS projects of various categories relevant to ship design. The use of one or more of these building blocks makes a flying start possible in the initiation of FLOSS for ship design. It is already possible to use FLOSS for some aspects of ship design today, and you will not have to pioneer the concept.

\section{References}

FSF (2001), Categories of Free and Non-Free Software, Free Software Foundation

GHOSH, R.A.; GLOTT, R. (2002), Free/libre and open source software: survey and study, Int. Inst. Infonomics, Univ. of Maastricht www.infonomics.nl/FLOSS/

GONZÁLEZ-BARAHONA, J.M. (2004), Quo vadis, libre software?, Universidad Rey Juan Carlos sinetgy.org/jgb/articulos/libre-software-origin/

MUTU, V.; IONAS, O.; GAVRILESCU, I. (2003), SURF - An in-house development for a ship hull design software, $2^{\text {nd }}$ Int. Conf. Computer and IT Applic. Mar. Industries, COMPIT, Hamburg, pp.387-399

RAYMOND, E.S. (1999), The cathedral \&5 the bazaar, O'Reilly, ISBN 1-56592-724-9

\{www.catb.org/esr/writings/cathedral-bazaar/

STALLman, R.M. (2002), Why "Free Software" is Better Than "Open Source", Free Software, Free Society, GNU Press, ISBN 1-882114-98-1

www.gnu.org/philosophy/free-software-for-freedom.html

VEELO, B.N. (2005), The potential for free software for ship design, $4^{\text {th }}$ Int. Conf. Computer and IT Applic. Mar. Industries, COMPIT, Hamburg, pp.399-418 